\title{
Correction to: Gene duplication and functional divergence of the zebrafish otospiralin genes
}

\author{
Aissette Baanannou ${ }^{1} \cdot$ Sepand Rastegar ${ }^{2} \cdot$ Amal Bouzid $^{1} \cdot$ Masanari Takamiya $^{2} \cdot$ Vanessa Gerber $^{2} \cdot$ Amal Souissi $^{1}$. \\ Tanja Beil ${ }^{2}$. Olfa Jrad ${ }^{1}$ • Uwe Strähle ${ }^{2}$. Saber Masmoudi ${ }^{1}$
}

Published online: 27 January 2020

(C) Springer-Verlag GmbH Germany, part of Springer Nature 2020

Correction to: Development Genes and Evolution. https://doi.org/10.1007/s00427-019-00642-8

In the originally published article, the first names and family names of the authors were interchanged, hence not correct. The correct presentation of names is presented above.

The online version of the original article can be found at https://doi.org/ 10.1007/s00427-019-00642-8

\footnotetext{
Aissette Baanannou

aissette.baanannou@yahoo.fr

1 Laboratory of Molecular and Cellular Screening Processes, Center of Biotechnology of Sfax, Sfax, Tunisia

2 Institute of Toxicology and Genetics, Karlsruhe Institute of Technology, 76021 Karlsruhe, Germany
} 